Int. J. Dev. Biol. 61: 329-335 (2017)

doi: $10.1387 / \mathrm{ijdb} .170012$ ts

\title{
Disruption of the aortic wall by coelomic lining-derived mesenchymal cells accompanies the onset of aortic hematopoiesis
}

\author{
ALAA A. ARRAF ${ }^{1}$, MARELLA F.T.R. DE BRUIJN² and THOMAS M. SCHULTHEISS ${ }^{*}, 1$ \\ ${ }^{1}$ Department of Genetics and Developmental Biology, Rappaport Faculty of Medicine, Technion-Israel Institute of \\ Technology, Haifa, Israel and ${ }^{2}$ MRC Molecular Haematology Unit, MRC Weatherall Institute of Molecular Medicine, \\ Radcliffe Department of Medicine, University of Oxford, Oxford, UK
}

\begin{abstract}
In vertebrates, definitive hematopoietic stem cells (HSCs) first emerge in the ventral wall of the aorta in the Aorta-Gonad-Mesonephros (AGM) region of the embryo, where they differentiate from a specialized type of endothelium termed Hemogenic Endothelium (HE). While the transition from $\mathrm{HE}$ to hematopoietic tissue has received much experimental attention, much less is known regarding generation of $\mathrm{HE}$ itself. The current study investigates the emergence of the HE in the chick embryo aorta. Using the HE marker Runx1 as well as a new chicken-reactive antibody to the endothelial marker VE-Cadherin, we document the relationship between the emerging HE and surrounding tissues, particularly the coelomic epithelium (CE) and CE-derived sub-aortic mesenchyme. In addition, the fate of the CE cells was traced by electroporation of a GFP-expressing plasmid into the $\mathrm{CE}$, followed by analysis using immunofluorescence and in situ hybridization. We make the novel observation that CE-derived mesenchyme transiently invades through the ventral wall of the aorta during the period of establishment of $\mathrm{HE}$ and just prior to the emergence of hematopoietic cell clusters in the ventral aortic wall. These observations emphasize a hitherto unappreciated dynamism in the aortic wall during the period of HE generation, and open the door to future studies regarding the role of invasive $\mathrm{CE}$-derived cells during aortic hematopoiesis.
\end{abstract}

KEY WORDS: hematopoiesis, hemogenic endothelium, coelomic epithelium, Runx1, VE-cadherin

\section{Introduction}

During vertebrate development, definitive hematopoietic stem cells (HSCs) exist as rare populations within blood-forming tissues that both self-renew and generate all blood cell lineages throughout the lifetime of the animal (Cumano and Godin, 2007; Orkin and Zon, 2008). Definitive HSCs are first detected as cell clusters budding from the ventral wall of the dorsal aorta in the Aorta-GonadMesonephros (AGM) region of the embryo (Dieterlen-Lievre and Martin, 1981; Taoudi and Medvinsky, 2007). Definitive HSCs have long been proposed to originate from a sub-type of endothelial cells called hemogenic endothelium (HE) (Dantschakoff, 1907; Swiers et al., 2013b). In vivo labeling experiments of chicken embryos suggested a precursor-progeny relationship between the ventral aortic endothelium and budding hematopoietic clusters (Jaffredo et al., 1998). Recent lineage tracing studies and time lapse imaging have visualized the in-vivo transition of endothelium into blood clusters, further supporting the hemogenic endothelium concept (Bertrand et al., 2010; Boisset et al., 2010; Kissa and Herbomel, 2010).

The ventral endothelium of the aorta and the subaortic mesenchyme express key markers of hematopoietic specification, including: Runx1, Scl/Tal1, Gata2 and C-myb (Bollerot et al., 2005; Chen et al., 2009; Shivdasani et al., 1995), and there has been extensive progress in understanding the role of these factors and others in the development of HSCs from HE. In contrast, much less is understood regarding the initial steps of aortic $\mathrm{HE}$ specification, both temporally and spatially. For example, it is not clear whether the haemopoietic properties of the ventral aortic lining are due to the presence of a special type of endothelium in that location, or to a special niche created by the adjacent ventral

Abbreviations used in this paper: AGM, aorta-gonad-mesonephros; CE, coelomic epithelium; EMT, epithelial to mesenchymal transition; GFP, green fluorescent protein; HE, hemogenic endothelium; HSC, hematopoietic stem cell.

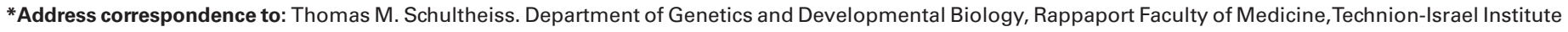
ofTechnology, 1 Efron Street, P.O. Box 9649, Haifa 31096, Israel. Tel: 972-4-829-5387. Fax: 972-4-853-5514. E-mail: tschulth@technion.ac.il
} 
subaortic mesenchyme or other tissues. Notch, Wnt, chemokine, and interferon signaling, among others, have all been implicated in the generation of hematopoietic tissue from the dorsal aorta (Clements et al., 2011; Espin-Palazon et al., 2014; Kobayashi et al., 2014; Sawamiphak et al., 2014); however, in many cases it is not clear whether these factors act on the HE-to-blood cell transition or on earlier stages, including generation of the HE itself. Studies in mouse suggest that HE may be specified quite early in development, days before the emergence of the first aortic hematopoietic clusters (Swiers et al., 2013a).

The stages prior to the appearance of aortic hematopoietic clusters are characterized by widespread morphological changes in the AGM region. Our previous studies and those of others have shown that the coelomic epithelium (CE) undergoes Epithelial to Mesenchymal Transition (EMT) to give rise to the sub aortic mesenchyme and dorsal mesentery, and that this subaortic mesenchyme plays an essential role in Runx1 endothelial cell expression and the formation of hematopoietic cells (Arraf et al., 2016; Richard et al., 2013). However, it is not known whether this mesenchyme plays a role in early aortic $\mathrm{HE}$ specification. In addition, during these stages the two dorsal aortae fuse into a single aortic vessel, and it is not understood whether this aortic fusion process is related to the establishment of aortic hematopoiesis.

In order to better understand the initial stages of aortic HE generation, we have conducted an integrated investigation of the early morphological and differentiation events during aortic hematopoiesis. We find that Runx1 expression begins in the lateral aorta when the aortae are still unfused and before the initiation of EMT in the CE, and that the emergence of the mature, ventral pattern of aortic Runx1 is accompanied by widespread invasion of the aortic wall by CEderived mesenchymal cells. These findings suggest possible roles for the CE and CE-derived mesenchyme during initiation of aortic hematopoiesis and also for other morphological events in the AGM region, including fusion of the dorsal aortae.

\section{Results}

\section{Markers of hemogenic endothelium, hematopoietic cells, and endothelium in the aorta-gonad-mesonephros region}

Runx 1 is essential for generation of blood, and has been extensively used as a specific marker for $\mathrm{HE}$ and hematopoietic precursors (Shivdasani et al., 1995; Swiers et al., 2013a). At HH St. 20, Runx1 is expressed in the ventral wall of the aorta both in hematopoietic clusters and in flat cells between the clusters, which presumably are $\mathrm{HE}$ (Fig. $1 \mathrm{~A}, \mathrm{~B}$ ). At this stage, the blood cell marker CD45 is expressed primarily in differentiating hematopoietic cells within the clusters and also in scattered cells within the aortic lining (Fig. 1E). We also generated an antibody to the highly specific endothelial marker VE-Cadherin (see the Experimental Procedures). Anti-VECadherin specifically labeled the endothelium in both the ventral and dorsal walls of the aorta, as well as other vessels (Fig. 1 C,D; see also Fig. 4). Within the CD45-expressing hemogenic clusters, VE-Cadherin was expressed at very low levels (Fig. 1 D,F, white arrow), while in more lateral regions of the aortic epithelium, some overlap of CD45 and VE-Cadherin could be seen (Fig. 1F, yellow arrows). Within the clusters themselves, light VE-Cadherin expression could be detected at the base of the clusters, where they are attached to the endothelium; whereas on the luminal side of the clusters VE-Cadherin expression was typically not detectable (Fig. 1D), in line with the lack of VE-Cadherin mRNA in these clusters (Jaffredo et al., 2005a).

\section{Dynamic expression of Runx1 in the aortic endothelium}

In order to better understand the early stages of HE generation, we aimed to find the earliest appearance of Runx1 in the dorsal aorta and to follow how its temporal and spatial expression progresses. The first appearance of Runx1 is at HH stage 14 (Fig 2A), where small numbers of endothelial cells on the lateral side of the un-fused aortae initiate expression of Runx1. As the aortae move medially
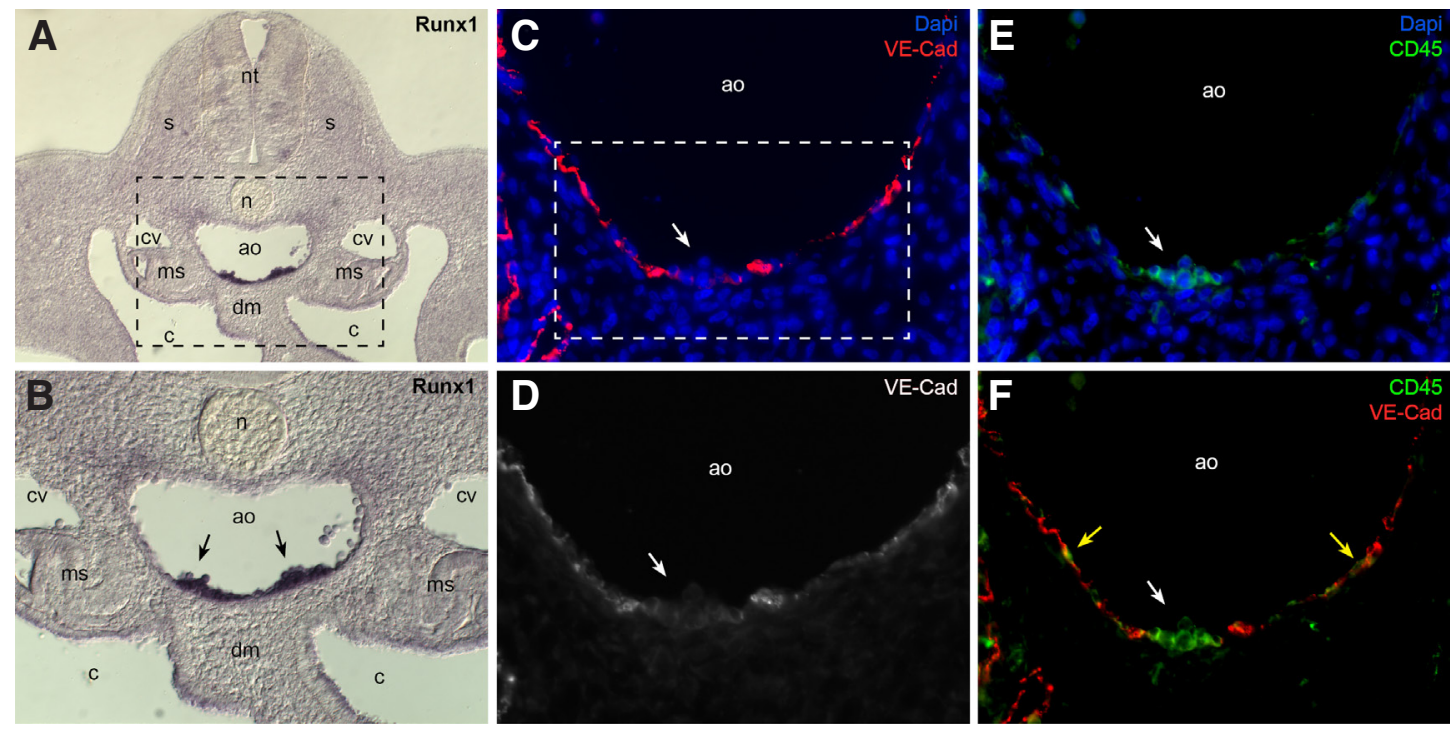

Fig. 1. Markers of hemogenic endothelium (HE), hematopoietic cells, and endothelium in the aorta-gonad-mesonephros (AGM) region. HH Stage 20 embryos in the AGM region stained by situ hybridization for Runx1 (A,B), or by immunofluorescence for DAPI, VE-Cadherin, and CD45 (C-F). Note the hematopoietic clusters budding from the ventral wall of the aorta (arrows in B; white arrows in C-F)), the expression of CD45 in cells of the hematopoietic clusters (white arrow in E, F), and the down regulation of VE-Cadherin at sites of cluster formation (white arrow in C,D,F). Abbreviations: ao, aorta; C, coelom; cv, cardinal vein; dm, dorsal mesentery; ms, mesonephros; n, notochord; nt, neural tube; s, somite. 

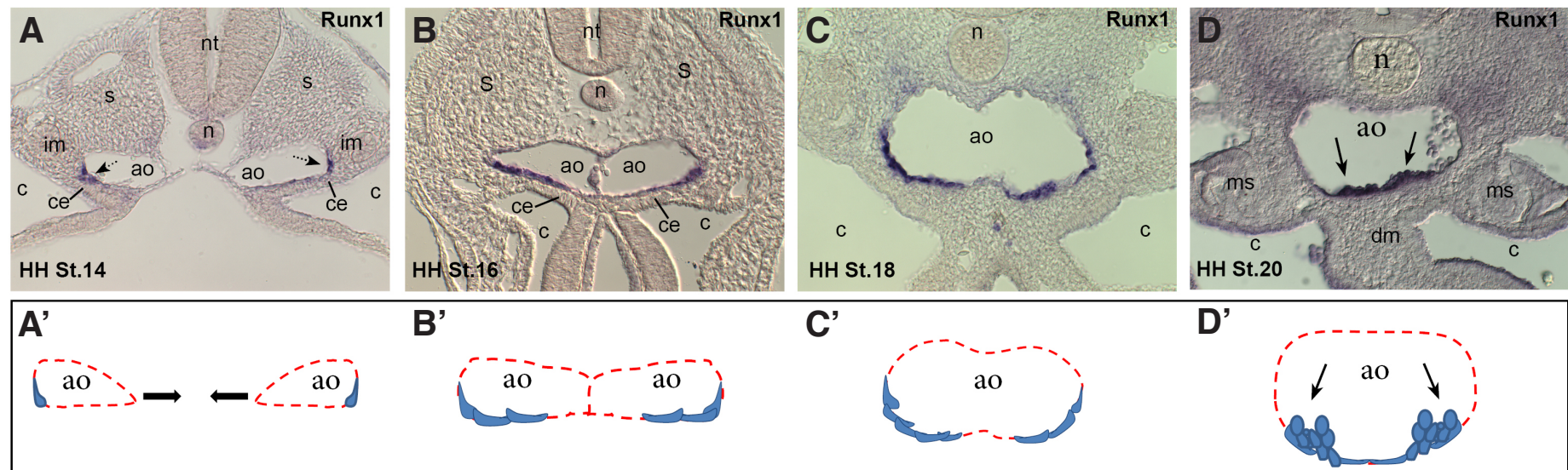

Fig. 2. Dynamic expression of Runx1 in the aortic endothelium. (A-D) In situ hybridization for Runx1 at different at the indicated stages. Runx1 first appears at HH St.14, when a small number of cells start to express Runx1 at the lateral side of the aorta, adjacent to the coelomic epithelium and the intermediate mesoderm [mark IM and CE])(dotted arrow). As the aortae move medially, Runx1 expression spreads ventrally (B,C). By HH St. 20, Runx1 expression is seen in the budding HSC clusters (D, arrow). ( $\mathbf{A}^{\prime}$-'D') show a model summarizing the progression of Runx1 expression in the aortic endothelium accompanying aortic morphological movements in the AGM, as shown in (A-D). Abbreviations: ao, aorta; $c$, coelom; ce, coelomic epithelium; dm, dorsal mesentery; im, intermediate mesoderm; ms, mesonephros; n, notochord; nt, neural tube; s, somite.

and begin to fuse, Runx1 expression spreads ventrally within the aortic endothelium (Fig 2 B,C). Subsequently, Runx1 expression is seen in the budding HSC clusters (Fig 2D). Looking at the dynamics of Runx1 expression from $\mathrm{HH}$ stage 14 to 20 , one can recognize a change in the tissue context of the Runx1-expressing cells. At early stages, the Runx1 expressing endothelial cells are in direct contact with the coelomic epithelium (CE) (Fig. 2 A,B, Fig. 3 A, A')), while at later stages, a layer of mesenchymal cells is found between the aorta and the CE (Fig. 2 C,D, Fig. 3 B,B').

\section{Coelomic epithelium-derived cells invade and move through the ventral wall of the aorta}

In a previous study, we documented that the CE of the AGM region undergoes an Epithelial to Mesenchymal Transition(EMT) to generate the mesenchyme of the subaortic region and the dorsal mesentery (Arraf et al., 2016). In accordance with the approach described in that paper, we labeled the coelomic epithelium by injecting a plasmid expressing Green Fluorescent Protein (GFP) into the coelomic cavity followed by electroporation (Fig. 4A). This method exclusively labels the pseudostratified epithelium that lines the coelomic cavity (Arraf et al., 2016). After 12-24 hours, labeled mesenchymal cells were seen extensively throughout the subaortic mesenchyme (Fig. 4 B,C). Remarkably, GFP-expressing cells

Fig. 3. The tissue context of the hemogenic endothelium changes during the progression of aortic hematopoiesis. $(\mathbf{A}, \mathbf{B})$ In situ hybridization of Runx 1 at the indicated stages. $\left(\mathbf{A}^{\prime}, \mathbf{B}^{\prime}\right)$ are magnifications of $(A, B)$ respectively. Initial expression of Runx 1 occurs when the aortic endothelium is in close contact with the coelomic epithelium (dotted arrows in $A^{\prime}$ ), while the initial process of cluster formation occur when the hemogenic endothelium is in direct contact with the coelomic epithelium-derived mesenchyme (arrows in $B^{\prime}$ ). Abbreviations: ao, aorta; $c$, coelom; ce, coelomic epithelium; cv, cardinal vein; im, intermediate mesoderm; $m s$, mesonephros; $n$, notochord; $n t$, neural tube; s, somite. could be seen joining the ventral aortic lining, and some of these CE-derived cells passed through the aortic wall into the lumen, disrupting and pulling VE-Cadherin positive cells from the aortic wall into the lumen (Fig. 4 D-L). The invasion of CE-derived cells though the aortic endothelium is a transient phase that occurs simultaneously with the fusion of the two aortae and before the appearance of CD45-expressing hematopoietic clusters in the lining of the aorta. By Stage 20, when CD45-expressing clusters are beginning to appear (Fig. 1), GFP cells are seen in the subaortic mesenchyme but not within the aortic endothelium itself (see Fig. 5C).

\section{Relation between the coelomic epithelium-derived cells and the hemogenic endothelium}

During the stages in which CE-derived cells invade the ventral aortic wall, expression of Runx1 is spreading medially-ventrally
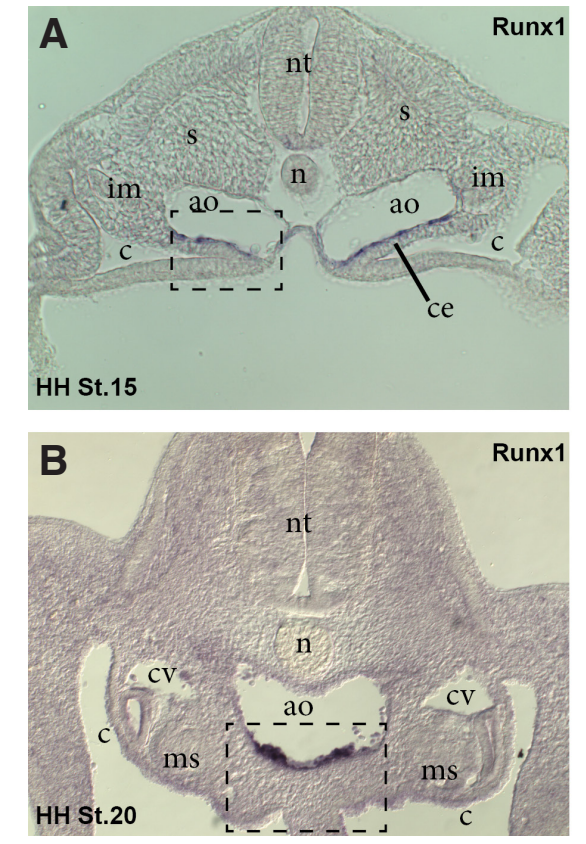
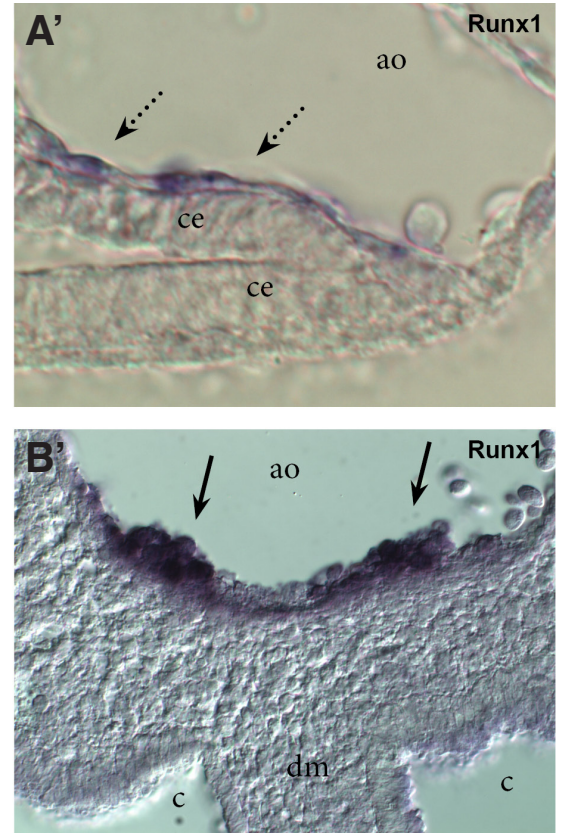
within the aortic endothelium (Fig. 2). In order to better understand the relationship between the CE-derived cells and the Runx1 positive cells, we conducted combined immunofluorescence/in situ hybridization for GFP and Runx1 on sections of CE-electroporated embryos. The results show that when the CE-derived cells are localized in the ventral wall of the aorta, there is no expression of Runx1 in this region (Fig. $5 \mathrm{~A}, \mathrm{~A}^{\prime}$ ), and that only after the CEderived mesenchymal cells have passed through the aorta does the Runx1-expressing hemogenic endothelium become localized to the ventral aortic wall (Fig. 5 B, B', C, C'). When Runx1 expression expands to the ventral wall of the fused aorta, CE-derived cells are located in the mesenchyme ventral to the aorta but not in the aortic lining itself (Fig. 5C).

\section{Discussion}

We have investigated the morphological movements and the tissue context of the early stages of HE specification in the AGM region. We used Runx1, a highly specific hematopoietic transcription factor to detect the temporal and spatial progress of HE specification. Consistent with previous reports (Jaffredo et al., 2005a; Jaffredo et al., 2005b; North et al., 1999; Richard et al., 2013), we find that aortic endothelial cells start to express $\mathrm{HE}$ markers at HH St.14, when Runx1 expressing cells appear at the lateral-most sides of the unfused aortae. We document that this initial expression occurs while the Runx1-expressing cells are in close contact with the coelomic epithelium, before the appearance of CE-derived mesenchyme. Subsequently, Runx1 expression spreads from that lateral corner to medial endothelial cells in the aortic floor, which are in close association with CE-derived subaortic mesenchyme cells. It is currently not clear whether the spread of Runx1 expression from lateral to medial occurs because Runx1 is activated in progressively more ventral aortic cells, or because lateral Runx1-expressing cells replicate and move ventrally.

The above findings indicate that, while the process of hematopoietic cluster formation occurs when the aortic endothelium is in close contact with the CE-derived mesenchyme, as was previously published (Richard et al., 2013), it seems that the initiation of $\mathrm{HE}$ specification occurs when the aortic endothelium is in direct contact with the CE, before the generation of sub aortic mesenchyme. This observation emphasizes the difference between the niche that governs the initiation of $\mathrm{HE}$ specification, which is poorly
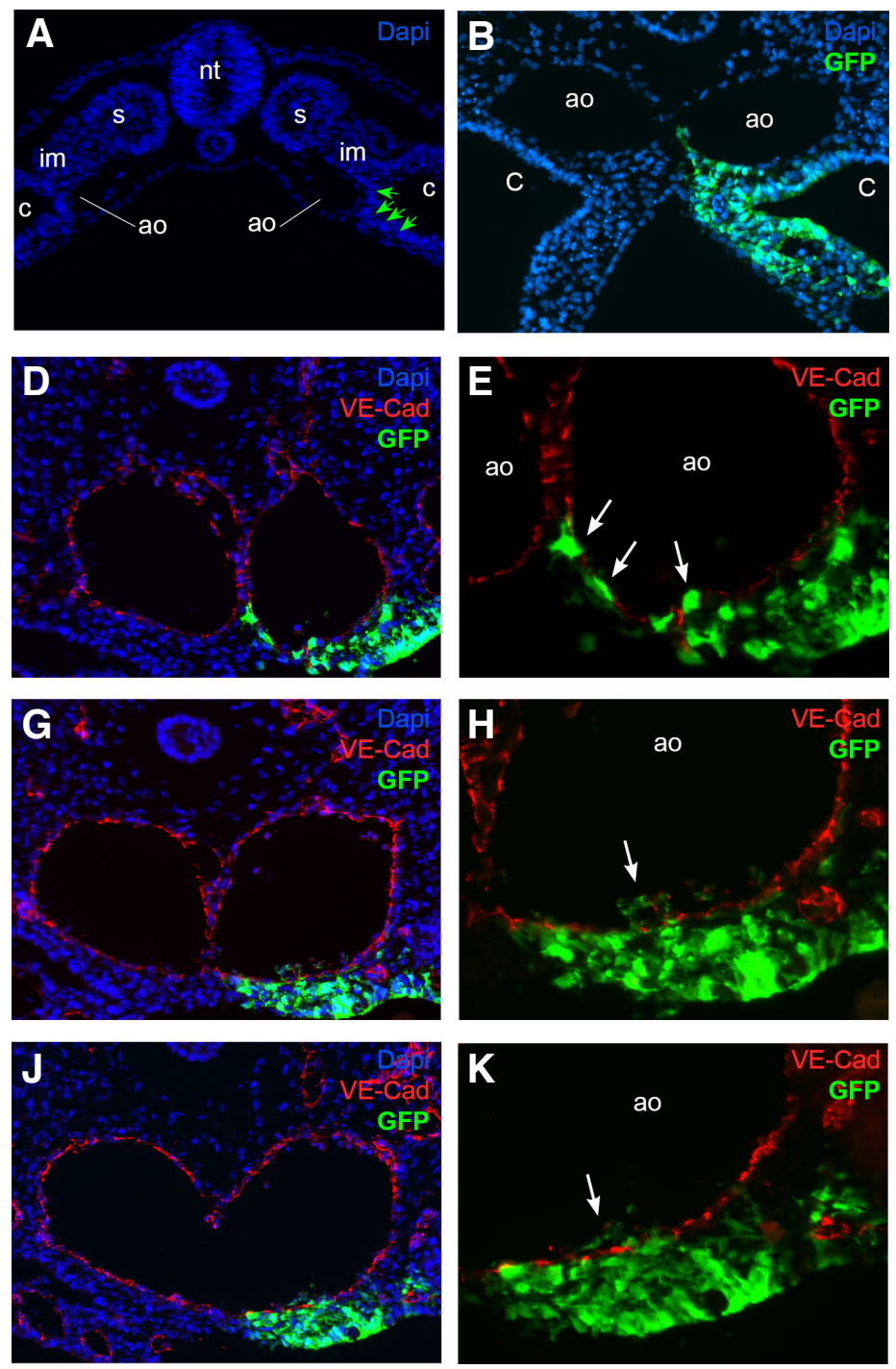
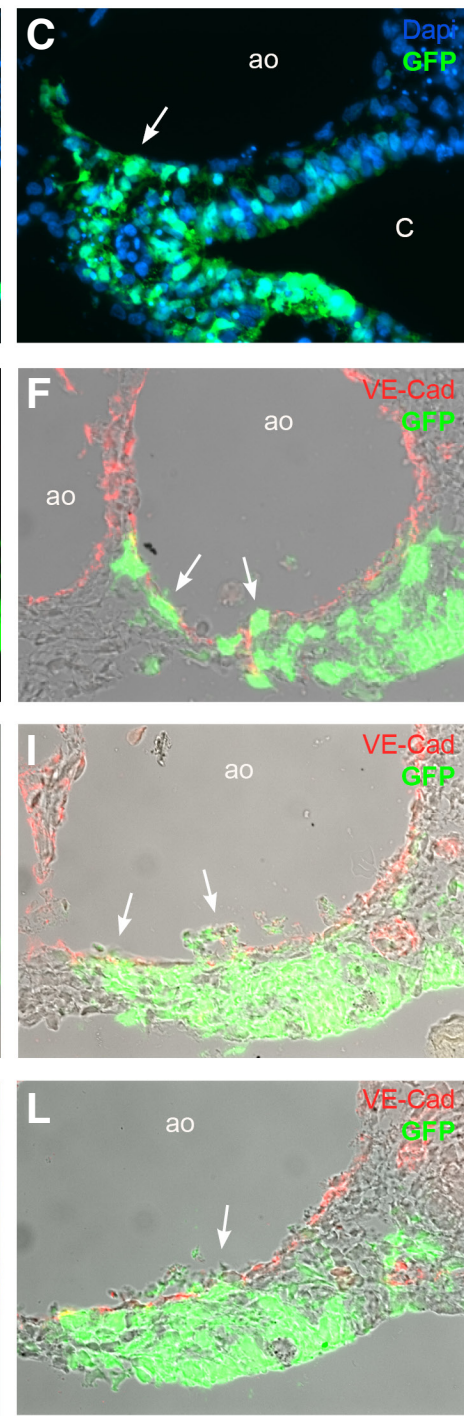

Fig. 4. Coelomic epitheliumderived cells invade through the ventral aortic lining just before the appearance of hematopoietic cells. (A) pMES Plasmid expressing GFP was electroporated into the CE in the region indicated by the green arrows at HHSt. 12-13. (B,C) After 24 hours (approximately Stage 17), CEderived cells were found throughout the sub-aortic mesoderm, coming right up to the aortic lining (arrow in C). (C) is a higher magnification of (B). (D-F, G-I, J-L) Sections moving from posterior to anterior axial levels, illustrating three progressively later stages in the aortic fusion process (aortic fusion occurs from anterior to posterior, so more anterior regions correspond to more advanced stages of the process). Arrows indicate CE-derived cells invading through the aortic lining and into the aortic lumen. $(E, H, K)$ are magnifications of $(D, G, J)$ respectively. $(F, I, L)$ are the same sections as $(E, H, K)$, but showing brightfield channel instead of Dapi. Abbreviations: ao, aorta; c, coelomic cavity; im, intermediate mesoderm; $n$, notochord; $n t$, neural tube; s, somite. 

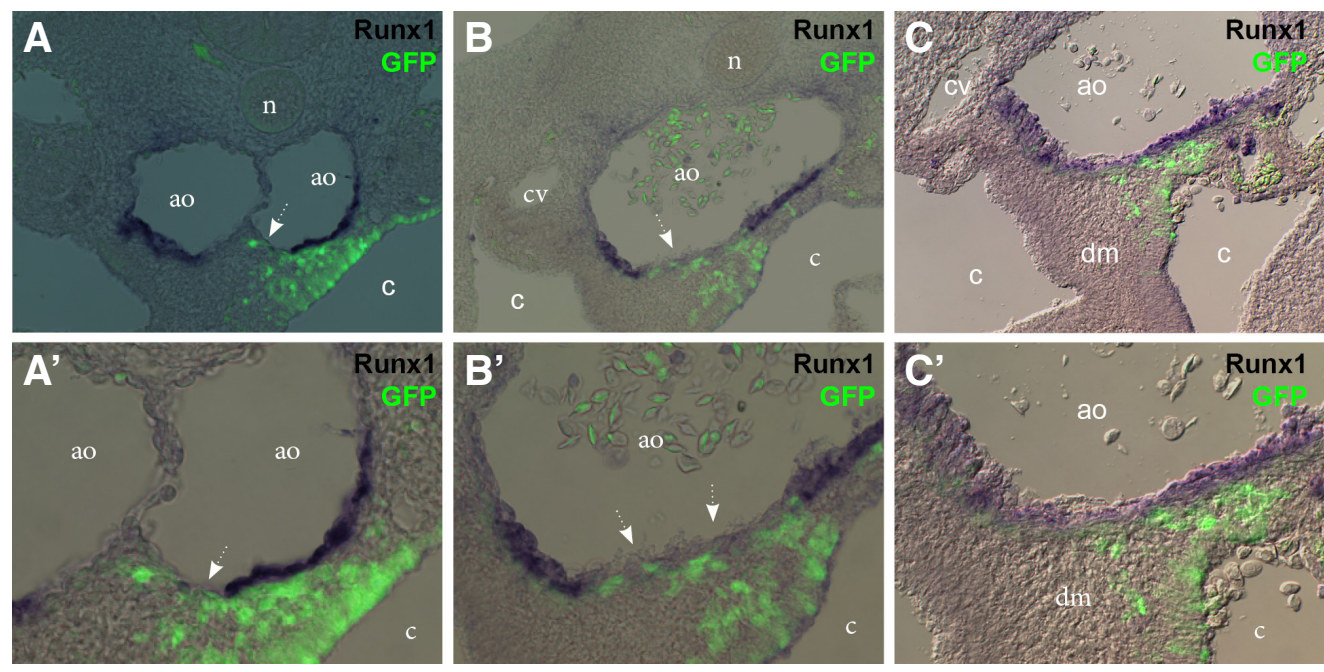

Fig. 5. Relation between coelomic epithelium-derived cells and hemogenic endothelium. Combined immunofluorescence/in situ hybridization for GFP and Runx 1 on sections of CE-electroporated embryos, at 24 hours after electroporation (approximately HHSt. 17; A, posterior, and $B$ anterior) and 48 hours after electroporation (C, approximately HHSt. 20). ( $\left.\mathbf{A}^{\prime}, \mathbf{B}^{\prime}, \mathbf{C}^{\prime}\right)$ are magnifications of $(\mathbf{A}, \mathbf{B}, \mathbf{C})$ respectively. At early stages of aortic fusion, CE-derived cells can be seen in the aortic wall medial to the Runx 1 expressing cells (A, A' dotted arrow), As Runx1 expression expands to the ventral wall of the fused aorta, CEderived cells can be seen in the mesenchyme ventral to the aorta but not in the aortic lining itself (B-C, $\left.B^{\prime}-C^{\prime}\right)$. The green fluorescence in the blood cells in the aortic lumen is autofluorescence. Abbreviations: ao, aorta; c, coelom; dm, dorsal mesentery; cv, cardinal vein; $n$, notochord.

understood, and the niche of hematopoietic cluster formation in the aortic floor, which has been much better studied. Studies that prevented the formation of subaortic mesenchyme by preventing CE-derived mesenchyme from reaching the aorta showed inhibition of aortic Runx1 expression and initiation of hematopoiesis (Richard etal., 2013). This result supports a requirement for coelom-derived cells for hematopoiesis, but since the manipulation was performed before EMT takes place, it is not clear whether it is the CE-derived subaortic mesenchyme or the CE itself that is required for Runx1 expression.

The AGM is a dynamic region that undergoes dramatic morphological changes and reorganization during the initial stages of aortic hematopoiesis. Two of the prominent processes taking place during this time are fusion of the dorsal aorta (Sato, 2013) and generation of the subaortic mesenchyme and adjacent dorsal mesentery (Arraf et al., 2016; Richard et al., 2013). Our studies and those of others showed that the coelomic epithelium is the source of the subaortic mesenchyme (Arraf et al., 2016; Richard et al., 2013), which is in close proximity to the aortic endothelium, but the contribution of CE-derived cells to the aortic floor itself was not clear. In the current study, we found that CE-derived cells invade through the ventral aortic wall, displacing endothelial cells from the aortic wall into the lumen. The invading CE-derived cells express neither VE-Cadherin nor Runx1. When one examines the relation between the invading cells and the $\mathrm{HE}$, one observes that the $\mathrm{CE}$ derived cells invade into the medial region of the aorta where there is no expression of Runx1. Only after the mesenchymal cells pass through the aorta does Runx1 expression spread into the most ventral region of the aortic wall. At this time, CE-derived cells can be found in the subaortic mesenchyme ventral to the aorta, but not within the aortic endothelial lining itself.

The origin of the endothelial cells of the dorsal aorta has been the subject of a number of studies. The splanchnic mesoderm is the primary source of the primitive dorsal aorta (Pardanaud et al., 1996). At later stages, somite-derived endothelial cells contribute to the roof of the aorta, which is not hemogenic, while the ventral wall of the aorta, which undergoes hematopoiesis, is of splanchnic lateral plate origin (Jaffredo et al., 2013). Later still, a second wave of somite-derived endothelial cells replaces the splanchnic mesoderm-derived cells in the ventral aortic wall, and this cell replacement is thought to contribute to the cessation of hematopoiesis in the ventral aortic wall (Pouget et al., 2006). The current results shows for the first time that there is an additional, transient, wave of cells derived from the coelomic epithelium that moves through the aortic floor just prior to the onset of hematopoiesis in the ventral aortic wall. One previous study hinted at the possibility of mesenchymal cells invading the aortic wall (Olah et al., 1988), but the origin of these cells is described here for the first time. The function of these invading cells is currently not clear. We find no evidence that they differentiate into hematopoietic tissue, as we were not able to find GFP+CD45+ cells (data not shown). It is reasonable to suppose that they may play a role in the fusion and remodeling of the aorta, which is taking place at this time. Whether they also play a role in initiation of hematopoiesis, for example by clearing out non-hemogenic endothelium and allowing for the ventral spread of specified $\mathrm{HE}$ from more lateral regions, or by perhaps signaling to the $\mathrm{HE}$, will be interesting to investigate in future studies. The current results also emphasize the dynamics of the cellular composition of the aortic lining. In future investigations, it will be interesting to determine whether other populations of cells also contribute cells to the aorta, and whether these populations play a role in hematopoiesis.

\section{Materials and Methods}

\section{In ovo electroporation}

Chicken eggs (Ross-308) were incubated at 38 degree $\mathrm{C}$ until $\mathrm{HH}$ stage 12-13. Embryos were staged according to (Hamburger and Hamilton, 1951).A circular window of about $2.5 \mathrm{~cm}$ diameter was made in the eggshell, and an Indian ink (Pelikan)/PBS solution (1:10) was injected into the subgerminal cavity to visualize the embryo. A solution of plasmid (1.2 $\mathrm{mg} / \mathrm{ml}$ ) and Fast green (0.05\%) was injected into the coelomic cavity at the level of the last somite, using a mouth pipette (Sigma) and a pulled glass microelectrode. Two tungsten wire electrodes were placed between the vitelline membrane and the ectoderm, and embryos were pulsed three times for $10 \mathrm{~ms}$ at $12-15 \mathrm{~V}$ using a BTX 830 electroporator. All the micromanipulation was performed under stereomicroscope (Leica). The injected 
embryos were sealed with beeswax and reincubated at 38 degrees $C$. in a humidified incubator for up to 48 hours.

\section{Expression plasmids}

The plasmid pMES was generously provided by C. Krull (Swartz et al., 2001). pMES is a bicistronic expression plasmid driven by a CMV/chicken beta-actin enhancer/promoter which drives strong, ubiquitous expression in chicken embryos and which contains eGFP driven by an IRES translation initiation element.

\section{Generation of anti-chicken VE-cadherin antibody}

The sequence KMLAELYGSEPNEDFVY, corresponding to the Cterminal 17 amino acids of chick VE-Cadherin (Genbank NM_204227) was synthesized, linked to KLH, and injected into rabbits (Sigma). Bleeds were tested on cryosections of chick embryos at serial dilutions, and a dilution of $1: 50,000$ was found to produce a strong signal completely specific to endothelial cells.

\section{Histological procedures, immunofluorescence, and in situ hybridization}

For cryostat sectioning, embryos were fixed in $4 \%$ paraformaldehyde overnight at 4 degrees $\mathrm{C}$. After serial washes with PBS, $5 \%$ sucrose/PBS, and $20 \%$ sucrose/PBS, the embryos were infiltrated with $7.5 \%$ gelatin $/ 15 \%$ sucrose/PBS overnight at 37 degrees $\mathrm{C}$. The next day, embryos were transferred to disposable embedding molds (Peel-Away, VWR) and allowed to solidify on ice. Subsequently, embryos were removed from the embedding mold, trimmed, and snap-frozen in Isopentane in a Dry Ice-Ethanol bath. Cryostat (Leica CM1900) was used to generate serial $10 \mu \mathrm{m}$ or 20 $\mu \mathrm{m}$ interval cryosections for immunonohistochimestry or in situ hybridization respectively, which was mounted onto glass slide (Superfrost Plus).

Immunohistochemistry was performed on cryosectioned embryos as previously described (Attia et al., 2012). The following primary antibodies were used: mouse or rabbit anti-GFP (1:500, Molecular Probes), mouse anti-chicken CD45 (1:100, Cedi diagnostics), and rabbit anti-chicken VECadherin (1:50000). Secondary antibodies used were Alexa488 or Cy3labeled Fab fragments (1:250, Jackson ImmunoResearch). Sections were counter-stained with DAPI ( $1 \mu \mathrm{g} / \mathrm{ml}$, Sigma) and mounted with Vectashield aqueous mounting medium (Dako). Sections were examined and imaged on a Zeiss Axioimager M1 upright microscope using a Qimaging ExiBlue monochrome camera and ImagePro Plus software.

Whole mount in situ hybridization was performed as previously described (Schultheiss et al., 1997) using digoxigenin labeled RNA probes for chick Runx1 (Castagnola et al., 1996). Following whole mount in situ hybridization, embryos were embedded in gelatin, cryosectioned at $20 \mu \mathrm{m}$ intervals, and photographed as above using DIC optics.

For combined in situ hybridization and immunofluorescence, whole mount in situ hybridization using digoxigenin labeled RNA probes for chick Runx1 and cryosectioning at $20 \mu \mathrm{m}$ intervals was performed as described above, followed by immunofluorescence for GFP using a polyclonal rabbit anti-GFP primary antibody (Molecular Probes).

\section{Acknowledgements}

We thank P. Castagnola and C. Krull for the generous gifts of plasmids. This work was supported by grants to T.M.S. from the Niedersachsen-Israel Research Cooperation program (VWZN2917), the Israel Science Foundation (1573/12), and the Rappaport Family Foundation.

\section{References}

ARRAF, A.A., YELIN, R., RESHEF, I., KISPERT, A., and SCHULTHEISS, T.M. (2016). Establishment of the Visceral Embryonic Midline Is a Dynamic Process that Requires Bilaterally Symmetric BMP Signaling. Dev. Cell 37: 571-580.

ATTIA, L., YELIN, R., and SCHULTHEISS, T.M. (2012). Analysis of nephric duct specification in the avian embryo. Development 139: 4143-4151.

BERTRAND, J.Y., CHI, N.C., SANTOSO, B., TENG, S., STAINIER, D.Y., and TRAVER,
D. (2010). Haematopoietic stem cells derive directly from aortic endothelium during development. Nature 464: 108-111.

BOISSET, J.C., VAN CAPPELLEN, W., ANDRIEU-SOLER, C., GALJART, N., DZIERZAK, E., and ROBIN, C. (2010). In vivo imaging of haematopoietic cells emerging from the mouse aortic endothelium. Nature 464: 116-120.

BOLLEROT, K., ROMERO, S., DUNON, D., and JAFFREDO, T. (2005). Core binding factor in the early avian embryo: cloning of Cbfbeta and combinatorial expression patterns with Runx1. Gene Expr Patterns 6: 29-39.

CASTAGNOLA, P., GENNARI, M., GAGGERO, A., ROSSI, F., DAGA, A., CORSETTI, M.T., CALABI, F., and CANCEDDA, R. (1996). Expression of runtB is modulated during chondrocyte differentiation. Exp Cell Res 223: 215-226.

CHEN, M.J., YOKOMIZO, T., ZEIGLER, B.M., DZIERZAK, E., and SPECK, N.A. (2009). Runx 1 is required for the endothelial to haematopoietic cell transition but not thereafter. Nature 457: 887-891.

CLEMENTS, W.K., KIM, A.D., ONG, K.G., MOORE, J.C., LAWSON, N.D., and TRAVER, D. (2011). A somitic Wnt16/Notch pathway specifies haematopoietic stem cells. Nature 474: 220-224.

CUMANO, A., and GODIN, I. (2007). Ontogeny of the hematopoietic system. Annu Rev Immunol 25: 745-785.

DANTSCHAKOFF, V. (1907). Uber das erste Aufreten der Blut-Elemente in Hühnerembryo. Folia Haematol 4: 159-166.

DIETERLEN-LIEVRE, F., and MARTIN, C. (1981). Diffuse intraembryonic hemopoiesis in normal and chimeric avian development. Dev Biol 88: 180-191.

ESPIN-PALAZON, R., STACHURA, D.L., CAMPBELL, C.A., GARCIA-MORENO, D., DEL CID, N., KIM, A.D., CANDEL, S., MESEGUER, J., MULERO, V., and TRAVER, D. (2014). Proinflammatory signaling regulates hematopoietic stem cell emergence. Cell 159: 1070-1085.

HAMBURGER, V., and HAMILTON, H.L. (1951). A series of normal stages in the development of the chick embryo. J Morph 88: 49-92.

JAFFREDO, T., BOLLEROT, K., SUGIYAMA, D., GAUTIER, R., and DREVON, C. (2005a). Tracing the hemangioblast during embryogenesis: developmental relationships between endothelial and hematopoietic cells. Int J Dev Biol 49: 269-277.

JAFFREDO, T., GAUTIER, R., EICHMANN, A., and DIETERLEN-LIEVRE, F. (1998) Intraaortic hemopoietic cells are derived from endothelial cells during ontogeny. Development 125: 4575-4583.

JAFFREDO, T., LEMPEREUR, A., RICHARD, C., BOLLEROT, K., GAUTIER, R., CANTO, P.Y., DREVON, C., SOUYRI, M., and DURAND, C. (2013). Dorso-ventral contributions in the formation of the embryonic aorta and the control of aortic hematopoiesis. Blood Cells Mol. Dis. 51: 232-238.

JAFFREDO, T., NOTTINGHAM, W., LIDDIARD, K., BOLLEROT, K., POUGET, C., and DE BRUIJN, M. (2005b). From hemangioblast to hematopoietic stem cell: an endothelial connection? Exp Hematol 33: 1029-1040.

KISSA, K., and HERBOMEL, P. (2010). Blood stem cells emerge from aortic endothelium by a novel type of cell transition. Nature 464: 112-115.

KOBAYASHI, I., KOBAYASHI-SUN, J., KIM, A.D., POUGET, C., FUJITA, N., SUDA, T., and TRAVER, D. (2014). Jam1a-Jam2a interactions regulate haematopoietic stem cell fate through Notch signalling. Nature 512: 319-323.

NORTH, T., GU, T.L., STACY, T., WANG, Q., HOWARD, L., BINDER, M., MARINPADILLA, M., and SPECK, N.A. (1999). Cbfa2 is required for the formation of intra-aortic hematopoietic clusters. Development 126: 2563-2575.

OLAH, I., MEDGYES, J., and GLICK, B. (1988). Origin of aortic cell clusters in the chicken embryo. Anat Rec 222: 60-68.

ORKIN, S.H., and ZON, L.I. (2008). Hematopoiesis: an evolving paradigm for stem cell biology. Cell 132: 631-644.

PARDANAUD, L., LUTON, D., PRIGENT, M., BOURCHEIX, L.M., CATALA, M., and DIETERLEN-LIEVRE, F. (1996). Two distinct endothelial lineages in ontogeny, one of them related to hemopoiesis. Development 122: 1363-1371.

POUGET, C., GAUTIER, R., TEILLET, M.A., and JAFFREDO, T. (2006). Somitederived cells replace ventral aortic hemangioblasts and provide aortic smooth muscle cells of the trunk. Development 133: 1013-1022.

RICHARD, C., DREVON, C., CANTO, P.Y., VILLAIN, G., BOLLEROT, K., LEMPEREUR, A., TEILLET, M.A., VINCENT, C., ROSSELLO CASTILLO, C., TORRES, M., et al., (2013). Endothelio-mesenchymal interaction controls runx1 expression and modulates the notch pathway to initiate aortic hematopoiesis. Dev Cell24:600-611.

SATO, Y. (2013). Dorsal aorta formation: separate origins, lateral-to-medial migration, 
and remodeling. Dev Growth Differ 55: 113-129.

SAWAMIPHAK, S., KONTARAKIS, Z., and STAINIER, D.Y. (2014). Interferon gamma signaling positively regulates hematopoietic stem cell emergence. Dev. Cell 31: 640-653.

SCHULTHEISS, T.M., BURCH, J.B.E., and LASSAR, A.B. (1997). A role for bone morphogenetic proteins in the induction of cardiac myogenesis. Genes Dev. 11: 451-462.

SHIVDASANI, R.A., MAYER, E.L., and ORKIN, S.H. (1995). Absence of blood formation in mice lacking the T-cell leukaemia oncoprotein tal-1/SCL. Nature 373: 432-434.

SWARTZ, M.E., EBERHART, J., PASQUALE, E.B., and KRULL, C.E. (2001). EphA4/ ephrin-A5 interactions in muscle precursor cell migration in the avian forelimb. Development 128: 4669-4680.
SWIERS, G., BAUMANN, C., O'ROURKE, J., GIANNOULATOU, E., TAYLOR, S. JOSHI, A., MOIGNARD, V., PINA, C., BEE, T., KOKKALIARIS, K.D., etal., (2013a). Early dynamic fate changes in haemogenic endothelium characterized at the single-cell level. Nature Comm. 4: 2924. doi: 10.1038/ncomms3924

SWIERS, G., RODE, C., AZZONI, E., and DE BRUIJN, M.F.T.R. (2013b). A short history of hemogenic endothelium. Blood Cell. Molec. Dis. 51: 206-212.

TAOUDI, S., and MEDVINSKY,A. (2007). Functional identification of the hematopoietic stem cell niche in the ventral domain of the embryonic dorsal aorta. Proc Natl Acad Sci USA 104: 9399-9403. 


\section{Further Related Reading, published previously in the Int. J. Dev. Biol.}

Definitive human and mouse hematopoiesis originates from the embryonic endothelium: a new class of HSCs based on VE-cadherin expression

Estelle Oberlin, Bouchra El Hafny, Laurence Petit-Cocault and Michèle Souyri

Int. J. Dev. Biol. (2010) 54: 1165-1173

https://doi.org/10.1387/ijdb.103121eo

The quest for hematopoietic stem cells in the embryo. An interview with Françoise Dieterlen-Lièvre

Thierry Jaffredo and Charles Durand

Int. J. Dev. Biol. (2010) 54: 1075-1078

https://doi.org/10.1387/ijdb.103153tj

Mpl receptor defect leads to earlier appearance of hematopoietic cells/hematopoietic stem cells in the Aorta-Gonad-Mesonephros region, with increased apoptosis

Maud Fleury, Laurence Petit-Cocault, Denis Clay and Michèle Souyri

Int. J. Dev. Biol. (2010) 54: 1067-1074

https://doi.org/10.1387/ijdb.103104mf

\section{Embryonic origin of human hematopoiesis}

Manuela Tavian, Katia Biasch, Lidia Sinka, Judith Vallet and Bruno Péault

Int. J. Dev. Biol. (2010) 54: 1061-1065

https://doi.org/10.1387/ijdb.103097mt

Aortic remodelling during hemogenesis: is the chicken paradigm unique?

Thierry Jaffredo, Charlotte Richard, Claire Pouget, Marie-Aimée Teillet, Karine Bollérot, Rodolphe Gautier and Cécile Drevon

Int. J. Dev. Biol. (2010) 54: 1045-1054

https://doi.org/10.1387/ijdb.103062tj

Tracing the hemangioblast during embryogenesis: developmental relationships between endothelial and hematopoietic cells

Thierry Jaffredo, Karine Bollerot, Daisuke Sugiyama, Rodolphe Gautier and Cécile Drevon Int. J. Dev. Biol. (2005) 49: 269-277

http://www.intjdevbiol.com/web/paper/041948tj

Embryonic development of the human hematopoietic system

Manuela Tavian and Bruno Péault

Int. J. Dev. Biol. (2005) 49: 243-250

http://www.intjdevbiol.com/web/paper/041957mt

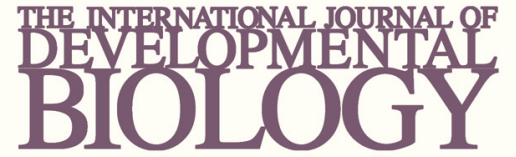

Volume 54 Nos. 6/7

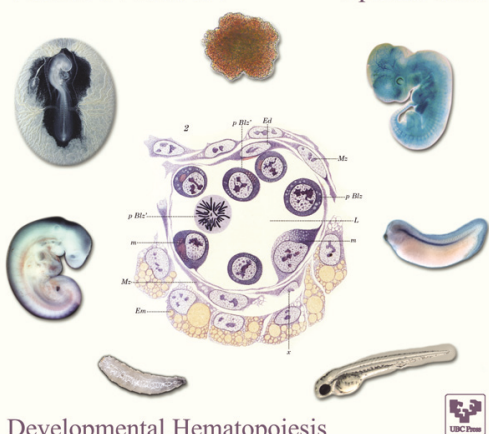

Developmental Hematopoiesis

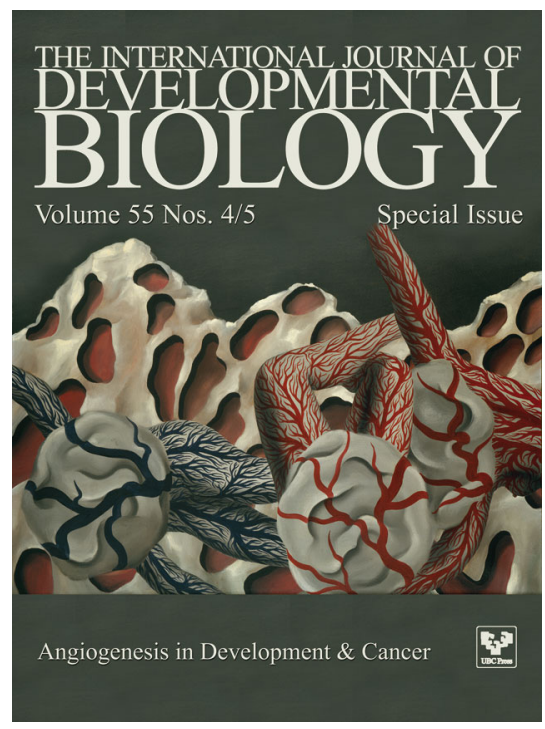

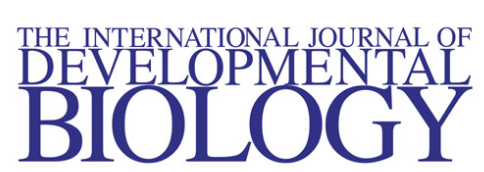

Volume 48 Nos. $5 / 6$

Special issue
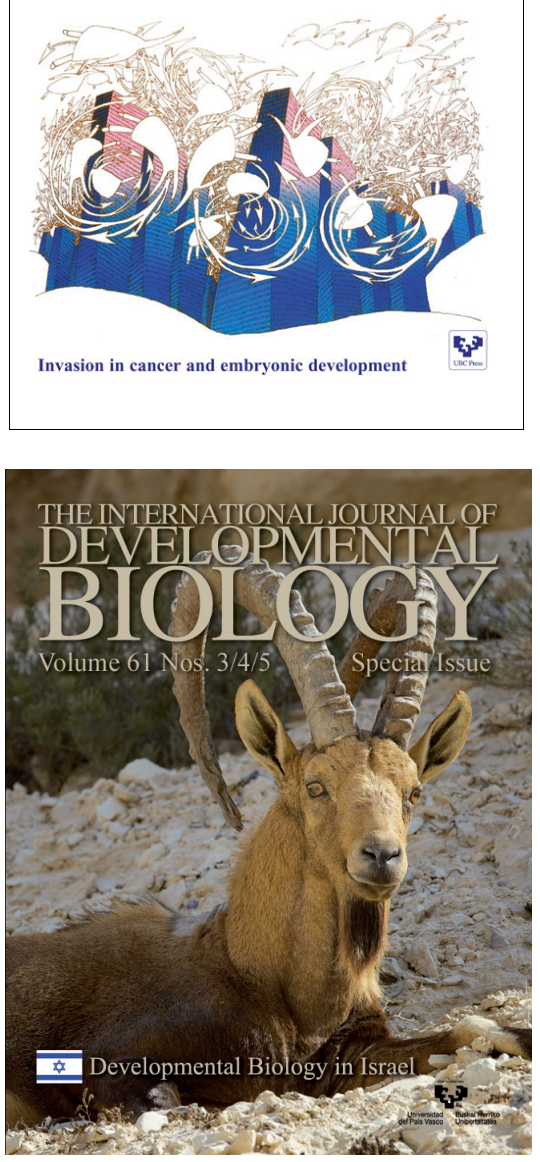